\title{
A Arte e os discursos intolerantes que a cercam
}

Alessandra Azevedo Jantorn ${ }^{1}$ Moema Martins Rebouças ${ }^{2}$ 


\section{Resumo}

Neste artigo o objetivo é de analisar discursos veiculados na mídia que propõem censura às Artes, para refletir e examinar como estas manifestações expõem valores e ideologias que disseminam a intolerância. Com referencial em Adorno a metodologia analítica para o estudo dos textos tem como base a proposição de Barros (2011) para o exame da construção discursiva de discursos intolerantes. $\mathrm{O}$ que se pretende é a contribuição para este debate por meio dos estudos da linguagem, possibilitando ao professor de artes intervenções críticas pautadas em argumentações que desvelem a intolerância que estes discursos carregam.

Palavras chave: arte e sociedade; discursos intolerantes; análise da arte.

\section{Abstract}

In this article the objective is to analyze discourses conveyed in the media that propose censors hip to the Arts, toreflectand examine how the se manifestations expose values and ideologies that spread intolerance. With reference in Adorno the analytical methodology for the study of the texts is based on the proposition of Barros (2011) for the examination of the discursive construction of in tolerant speeches. What is intended is the contribution to this debate through language studies, enabling the art teacher to intervene critically based on arguments that expose the intolerance that these discourses carry.

Keywords: art and society; intolerant speeches; art analysis.

ISSN: $2175-2346$ 
[...] os preconceitos servem para consolidar e manter a estabilidade e a coesão da integração dada. Eles aumentam em momentos em que a coesão econômico, política e ideológica de uma dada integração social diminui: por exemplo, quando a coesão nacional é debilitada pelas lutas de classe, a coesão da classe pela luta entre partidos [...]. O aumento de preconceitos pode, em tais circunstâncias, se acelerar, muitas vezes como produto de manipulação política (PATTO, 2008, p. 23).

\section{A função social da arte}

Há pelo menos 50 anos, Theodor Ludwig Wiesengrund-Adorno concebia Arte como o único agente social transformador, capaz de promover uma razão emancipadora e o crescimento crítico dos focos populacionais. Ele, certamente, instruiu seus discípulos e colaboradores de que a Arte é o único caminho para a formação de uma razão crítica em frente à opressão social vigente. Em 1923 conheceu seus dois principais parceiros intelectuais - Max Horkheimer e Walter Benjamin,esse último no qual também vamos (re)visitá-lo em seu conceito de inconsciente óptico.

Numa tentativa de romper o caráter linear do tempo nas obras de artes, Adorno expõe a problemática de maneira que a Arte Moderna seja constituída de tal forma que se transforme puramente em uma mercadoria, visto que é possível, nas sociedades atuais, que os produtos artísticos visem a traduzir, no plano estético, o declínio da ideologia burguesa. Mais uma vez propõe que a Arte deve ser considerada como um verdadeiro agente social transformador, e não como uma espécie de espelho no qual se refletiriam os ferimentos da decomposição social. A objetivação da Arte é condenada por Adorno, visto que é preciso que ela escape a todo e qualquer tipo de aparência (necessária ao mundo capitalista), e retome o contexto subjetivo das humanidades, visto que sua utilização atual vem sendo projetada nas necessidades subjetivas falseadas pela ideologia dominante.

Para Adorno, a obra de arte e o processo artístico, por meio dos mais variados métodos, adquirem a sua grandeza unicamente por fazerem falar o que é encoberto pela ideologia. A poesia, a música e as artes em geral exigem uma autonomia que, por sua vez, implica protesto contra um estado social aparentemente inimigo da sociedade e essa representação está contida nas obras de alguns artistas tradicionais e contemporâneos. Para ele, o artista pode ser concebido tanto como criador como representante. Ele é tanto representante da tendência social global, como é sujeito dessa própria ação. Essa mediação se faz necessária para a produção e transformação social, visto que o artista e o arte-educador tem à sua frente instrumentos necessários à reflexão e à expressão que podem ser utilizados com consciência social e linguagem adequada ou como "falseabilidade" da realidade social vigente. O conteúdo de verdade das obras de arte, transcrição histórica inconsciente, é então histórico na medida em que a consciência verídica se objetiva na obra: esta consciência não é um mero ser no tempo: um kairós; este justificaria o curso do mundo, o qual não é desdobramento da verdade. A consciência verídica é muito mais [...] (ADORNO, 1977, p. 56).

Para Adorno, a função educadora da Arte perpassa o caráter meramente demonstrativo da realidade empírica e assume formas de comprometimento com a 
transformação cultural e crítica em frente às verdadeiras necessidades sociais.

Para o autor, a arte-burguesa, integrada pela ideologia dominante, opõe-se às tentativas artísticas que medem, dia após dia, o fosso entre a essência afirmativa da arte e a realidade. É pela renúncia ao seu poder de crítica social que a obra de arte perde todo seu caráter de práxis real no interior da realidade empírica e se torna objeto de desejo, artigo de consumo e promessa de uma felicidade imediata e efêmera caracterizada pela sua posse.

Adorno ainda acentua a alternativa perante a qual se encontram em nossos dias as práticas artísticas, obrigadas, ao mesmo tempo, a agradar e a oferecer aos homens a possibilidade de questionar seu modo de existência alienada.

Numa tentativa de caracterizar a arte como única saída para a transformação cultural e social, Adorno compreende de forma pessimista que, se a Arte não se colocar como tal, ela poderá desaparecer diante do sistema capitalista e financeiro. Isso se dará devido à sua concepção como mercadoria de consumo e não como agente capaz de educar, transformar, transmitir valores e questionar sua própria neutralização "revolucionária"

É com este referencial que este artigo faz uma reflexão sobre as recentes manifestações de grupos sociais organizados como o Movimento Brasil Livre-MBL, uma organização criada pra transformar o país, nos diversos níveis sociais, políticos e culturais.

A apresentação na abertura da 35 Mostra Panorama da Arte Brasileira, no Museu de Arte Moderna de São Paulo realizada pelo artista carioca Wagner Schwartz é uma performance em que o artista se torna um bicho da série de Ligia Clark ${ }^{3}$, e diferente das obras da artista feitas de metal, oferece o seu próprio corpo, como corpo-obra para em conformidade com a série da artista, poder ser manipulado pelo público. A performance é denominada "La Bête".

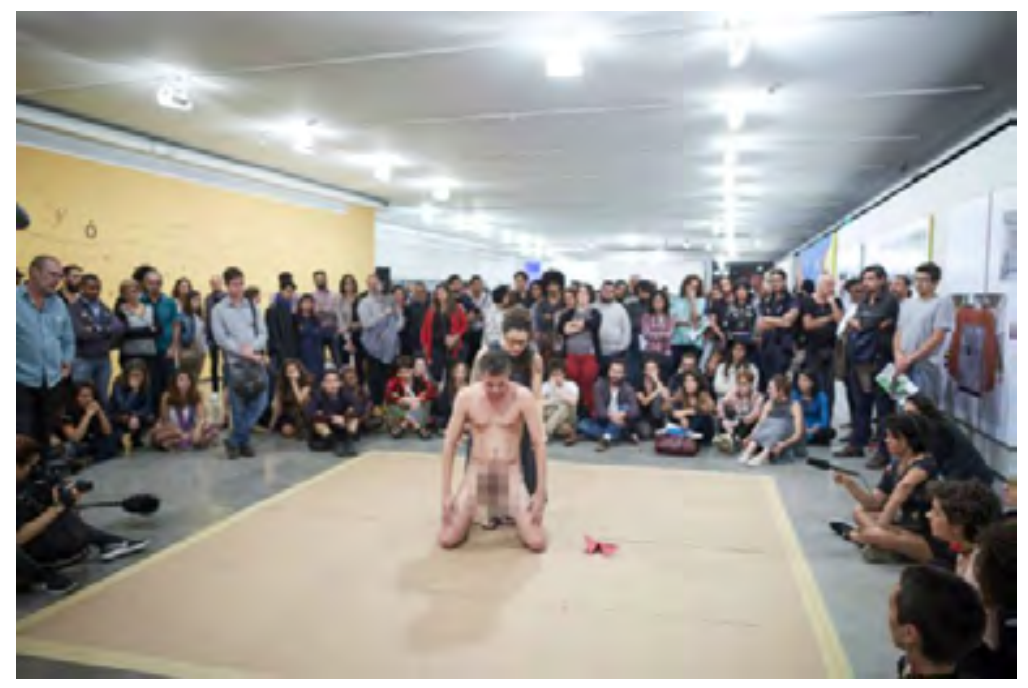

"La Bête", MAM, 2017.

Fig 1: https://www.cartacapital.com.br/sociedade/o-nu-esta-em-todos-os-museus-do-mundo.

3 Os "Bichos"da artista Lígia Clark compõem uma série de obras realizadas nos anos 1960 a 1964, que tem como principio a articulação escultórica o que permite a manipulação para quem com elas interagir. 


\section{Construção discursiva da intolerância}

A performance parcialmente recortada, como se a parte filmada representasse o todo da obra é divulgada nas redes sociais pelo $\mathrm{MBL}$, com a acusação de incitar à pedofilia.

Em primeiro momento é bom esclarecer o que é Pedofilia ${ }^{4}$. Pedofilia é uma parafilia termo muito diferente de atentado contra a criança vulnerável, ou abuso de vulneráveis ${ }^{5}$, esse é o crime. Pedofilia é um transtorno psicológico causado na sua maioria por abusos sexuais na infância, $80 \%$ a $90 \%$ de pessoas que sofrem esse transtorno foram abusadas sexualmente na infância por criminosos sexuais, as pessoas constantemente misturam esses conceitos.

Recentemente uma onda incitada por políticos "todos contra a Pedofilia" nos remete ao um erro de conceito que vem confundindo muita gente. Pedofilia é quando um sujeito se estrutura de uma maneira doente sua sexualidade à padrões infantis. Ele normalmente não possui relações sexuais normais, com a esposa, a amante ou affairs. O indivíduo que sofre de pedofilia nem sempre, e raramente procura a prática de sexo no outro (a criança), ao contrario dos abusadores, que possuem esposas, famílias, amantes e ainda buscam prática de sexo com crianças.

O problema surge quando uma criança é abusada antes de fases essenciais de seu desenvolvimento sexual, derivando assim traumas e desconstrução psíquica. Normalmente a psique começa a ser estruturada por volta de dois a três anos de idade, o que nos leva a considerar que a criança nessa idade tem uma boa estruturação psíquica (JUNG, 1968). Já a sexualidade é por volta dos 7 anos de idade que começa a diferenciação dos gêneros. Por outro lado, as crianças se utilizam dessa dicotomia para criar uma ferramenta e um instrumento de conduta, ou seja, um guia de atitudes sociais e éticas que, apoiada pela família, e a estrutura religiosa, seque no seu ritmo normal as bases do fundamentalismo para o reconhecimento dos gêneros. Dessa forma uma exposição artística não tem nenhuma relação com a pedofilia. A criança que participou fez uma abordagem de curiosidade intrínseca a sua idade.

O que se viu na performance do artista e coreógrafo foi a colocação do corpoobra, e a presença nas mãos do artista de uma pequena réplica de plástico, de uma das esculturas da Lígia Clark da série Bicho, sendo movimentada por ele como a convidar o público a interagir em seu corpo-obra.

Importante esclarecer tratar-se de um espaço fechado de Museu, e o MAM esclareceu que o ambiente em que ocorreu a performance estava devidamente sinalizado, e com a presença de um público composto principalmente por artistas, por trata-se de abertura de evento. A parte filmada e colocada nas redes sociais por integrantes/simpatizantes do MBL é quando a filha da performer e coreógrafa Elisabeth Finger, toca os pés do artista, que se encontra deitado. Na noticia da rede

\footnotetext{
4 Pedofilia Seu significado etimológico é, portanto, "amor pelas crianças". No entanto, segundo o uso atual, a palavra não procede diretamente do grego, mas foi introduzida no vocabulário médico pelo psiquiatra vienês Richard von Krafft-Ebing através da sua obra PsychopathiaSexualis, publicada em 1886, para definir a atração sexual primária para indivíduos impúberes ou de puberdade temporã. A definição médica oficial é a da Classificação Internacional de Doenças da Organização Mundial da Saúde, definem a pedofilia como uma atração sexual primária para crianças pré-pubescentes ou de puberdade temporã e a consideram um transtorno mental e da conduta
}

5 Estupro de vulnerável é ainda a pessoa que "por qualquer outra causa, não pode oferecer resistência" (art. 217 , $\left.\S 1^{\circ}\right)$. Refere-se à lei neste ponto a qualquer pessoa que se encontre na situação de não poder oferece rresistência à conduta do agente. 
social, a informação da presença da mãe é omitida, o que é divulgado é a reação à parte do que foi filmado. Ressalto este aspecto, pois o estudioso do texto verbal, visual, ou audiovisual, sabe como a parte não representa o todo, e como a omissão é uma estratégia de manipulação para fazer-parecer-ser que é verdade o que é mentira, pois transforma o que é e parece no que parece não ser. Conforme Greimas (1993), a veridicção é uma estratégia que ao determinar o estatuto veridictório de um discurso impõe valores a serem trocados, como neste caso, serem disseminados nas redes sociais. A verdade, como é, e parece ser, estava restrita somente aos que naquele ambiente compartilharam a performance do artista. Ainda para o semioticista, a atribuição de verdade ou de falsidade de um discurso dependem de três fatores: do tipo de discurso, da cultura em que ele é destinado e da sociedade, assim o que vale na mesma época para um grupo social, não é para outro. Portanto, a aceitação do discurso nas redes sociais dependem da persuasão do enunciador, neste caso os integrantes do $\mathrm{MBL}$, reconhecidos por determinado grupo social pelo que dizem fazer e lutar, e os que "acreditam neles", são aqueles que compartilham os mesmos ideais, princípios e convicções que o enunciador, neste caso o MBL. A estratégia é de apagamento, e se dá com os recursos da tomada da parte pelo todo, e do uso das redes sociais. O discurso manipulado em sua forma, como parte de um acontecimento, e direcionado faz-ver e faz saber, tal como uma manobra cognitiva discursiva.

O que queremos acentuar até então neste artigo, é que ao recortar um fato e tomar a parte pelo todo com o intuito de disseminar este conteúdo forjado nas redes sociais para acusar o artista de pedofilia, reconhece-se tais ações como pertencentes a um discurso da intolerância. Para Barros (2011, p.255) os discursos intolerantes e preconceituosos apresentam quatro tipos de construção discursiva:

Os de organização narrativa, sobretudo do percurso de sanção; os de constituição dos percursos passionais, com base nos estudos da modalização, da aspectualização e da moralização discursivas; os da elaboração dos temas e das figuras semânticas do discurso, que mais claramente expõem suas determinações ideológicas; os da formação da organização geral do discurso, na perspectiva de sua tensividade.

No exame do fato promovido pelo MBL, temos uma organização narrativa que sanciona negativamente a arte e, principalmente o artista, como se ele fosse pedófilo e o nu inaceitável, conforme trecho retirado de jornal de ampla circulação que comenta o fato.

O MBL divulgou um vídeo nas redes sociais em que chama a apresentação de "repugnante", "inaceitável", "erotização infantil", "afronta", "crime”, e afirma que a criança "se sentiu constrangida". O grupo acrescenta que o vereador Fernando Holiday (DEM) vai "tomar as providências sobre o caso da criança induzida a ato libidinoso"6.

Neste mesmo trecho do jornal, é possível constatar a segunda característica do discurso intolerante, qual seja o percurso passional de ódio, caracterizada como paixão excessiva por Barros (2011). Conforme a autora nos discursos intolerantes uma 
característica é a existência das paixões malevolentes como a antipatia, o ódio, a raiva, etc. Para o grupo disseminador, o MBL, o artista não cumpriu um acordo social e esta é a justificativa para a ação contra ele. Para Greimas (1983), o sujeito preconceituoso passa a ação e age sobre o outro (o odiado), em nosso caso, contra o artista com intuito de vingança. Algo que é da esfera do acontecimento de um grupo social, em um espaço que é publico, mas é fechado; com determinados destinatários, aqueles que neste espaço fechado assistiam, ao ir para as redes sociais e ao transformar em publico e aberto, faz do artista um criminosa, conforme palavras divulgadas pelo movimento.

A terceira característica do discurso intolerante apontada por Barros(2011) é a presença de temas e figuras relacionadas à oposição semântica fundamental presente nestes tipos de discursos, como a igualdade ou identidade e, a diferença ou alteridade. Cabe esclarecer que os temas e as figuras fazem parte do nível mais superficial do discurso e como são variáveis, são determinados sócio-historicamenteportanto, criam nos discursos possibilidades de interpretação do mundo, em conformidade com as classes, grupos em que estão inseridos, o que faz com que determinem o caráter ideológico dos discursos. Barros (2011, p.264) aponta quatro percursos temáticos e figurativos nos discursos intolerantes ao tratarem da diferença:

A animalização do "outro"; a "antinaturalidade" do diferente; o caráter doentio da diferença; a imoralidade do "outro".

A isotopia do criminoso está no encadeamento das palavras "repugnante", "inaceitável", "erotização infantil", "afronta", "crime", como ato do artista à criança, citadas pelo vereador cina nota do jornal.

Podemos reconhecer estes percursos temáticos e figurativos nos vídeos divulgados, e podemos num percurso diacrônico ir para o passado e encontrar outros discursos intolerantes atribuídos a outros artistas.

Na exposição de Anita Malfatti, realizada em 1917 a artista rompe com a estética da época realizando uma exposição com as suas obras modernistas, o que causa crítica feroz e demolidora de Monteiro Lobato, divulgada em jornal de ampla circulação, e como resultado a artista foi rejeitada pela elite paulistana. Tal fato, entretanto preparou a sociedade para o que viria mais tarde na Semana de Arte de 1922 (ALMEIDA, 1976).

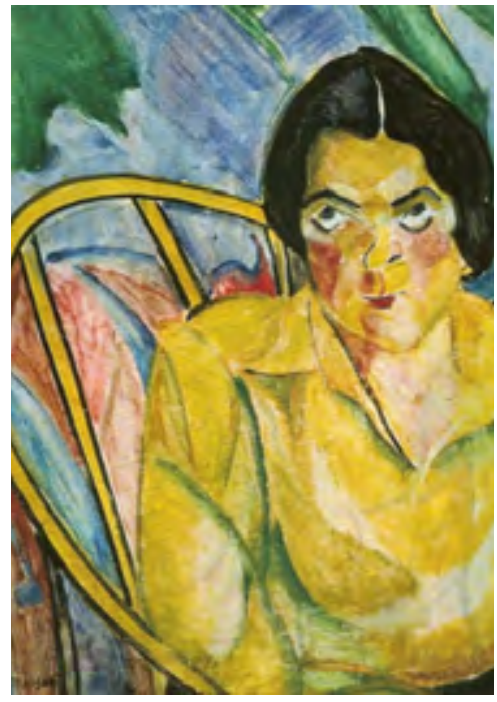

Fig.2: Anita Malfatti, A Boba, 1916. Museu de Arte Contemporânea de São Paulo. 
Outros incidentes ocorreram como durante a leitura do poema "Os Sapos", de Manuel Bandeira, o público presente no Teatro Municipal fez coro e atrapalhou a leitura, mostrando desta forma a desaprovação No dia 17 de fevereiro, Villa-Lobos fez uma apresentação musical. Entrou no palco calçando num pé um sapato e em outro um chinelo. O público vaiou, pois considerou a atitude futurista e desrespeitosa (DUILIO, 2008).

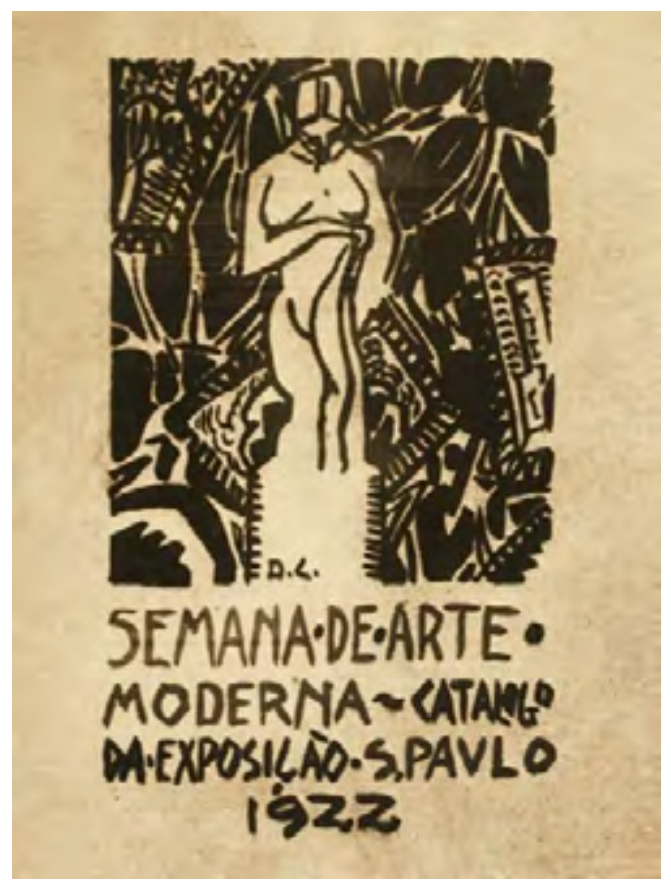

Fig. 3: Capa do catálogo da exposição, desenhado por Di Cavalcanti. (Imagem: Acervo/Theatro Municipal de São Paulo)

Os exemplos de intolerância citados, embora sejam muito agressivos, restringemse à uma discordância estética, diversa das acusações e posicionamentos que temos presenciado, tanto no caso da abertura da 35을 Mostra Panorama da Arte Brasileira, no MAM-SP, como no movimento que como consequência encerrou a exposição "Queermuseu: cartografias da diferença da arte", na Fundação Cultural de um banco em Porto Alegre neste ano de 2017.

Quanto à quarta característica dos discursos intolerantes apontada por Barros (2011, p.268) está a organização tensiva de tais discursos: a do exercício e a do acontecimento. O exercício caracteriza-se como o discurso dos fatos extensos e ordinários, enquanto o do acontecimento pertence aos fatos intensos e extraordinários.

Como os discursos intolerantes são passionais, pertencem ao acontecimento e se justificam ao atrelarem-se a outros discursos, como a pedofilia, no caso do discurso em análise. Ou a sequencia que temos acompanhado destes discursos em torno da censura às Artes.

Para que possamos reverter os discursos da intolerância é preciso que os valores descritos sejam revertidos aos aqui apontados. Como então isso pode ser feito? 


\title{
Reverter, transformar
}

\begin{abstract}
$\mathrm{Na}$ atualidade, há dois domínios que concernem à atividade humana: a política e a sexualidade, no plano individual e no coletivo. Com uma teoria da prática política, de um lado, e do outro, uma teoria da sexualidade, temos necessariamente as bases de uma moral (FOUCAULT, 2011, p. 162).
\end{abstract}

Segundo nosso filósofo a Arte, como pertencente ao plano de educação de uma determinada sociedade, tem um caráter significativo diante das mudanças de atitudes e de valores dos quais os indivíduos se encontram enraizados e alienados. Com o aumento da consciência social, esses cidadãos serão formados indivíduos críticos e capazes de analisar o contexto social no qual estão inseridos e, ao mesmo tempo, promover a denúncia das múltiplas formas de integração da Arte pela ideologia dominante, tais como o fato analisado da disseminação do vídeo pelo $\mathrm{MBL}$, e outros acontecimentos após este, como a lei proposta pelo Deputado Euclério Sampaio, do estado do Espírito Santo para censurar exposições que contivessem o nu. Esta proposta ao passar pela Assembléia Legislativa do estado do Espírito Santo, teve somente um único voto contrário ${ }^{7}$.

Tais acontecimentos ao invés de quebrar a dualidade do paradigma binário, ricopobre/ branco-negro/ sujo-limpo e nu ou vestido, reforça o poder de censura para determinado grupo social, como se estes assumissem a posição de censores para que pode e o que não pode se apresentar como arte. Quando se pensava que os tabus exigidos na idade média já tivessem sido aniquilados, acompanhamos o retorno e a sanção de parte da sociedade em apoio a estas ações. E quais serão os motivos verídicos dos tabus da contemporaneidade?

A função simbólica, e artística nos remete ao princípio do homem simbólico, a função da arte sempre foi uma função reflexiva de fomento a critica e a transformação social, resta-nos saber que com o passar do tempo a Arte sempre sofreu sanções e manipulações dos governos, dos sistemas dominantes, e da burguesia.

As manifestações que estão ocorrendo no país, são de fatos uma nova censura, que advém de momentos históricos críticos e que trazem a luz uma critica a desigualdade de pesos entre os sistemas e suportes de veiculação. A exemplo do que passa nos canais abertos das televisões, nas novelas e o que ocorre em um museu. $O$ que é permitido e veiculado pelas grandes mídias não pode ser tomado como referencia de intolerância para estes grupos?

A mais passional da intolerância é o preconceito, e a Arte tem como uma de suas principais funções simbólicas a descoberta e descortinação dessa ideia préconcebida e distante do diferente, ser igual é ser inserido em um contrato social pré estabelecido. Ou seja, nos textos analisados e apresentados qual é o papel do ensino aprendizagem de Artes? Entre as respostas estáa de favorecer o ambiente para que o aluno saiba e compreenda o papel da arte na sociedade, sem tirar a autonomia do sujeito em questão, levando-o a um nível de consciência que vai além de suas

7 A votação ocorreu na última semana do mês de outubro de 2017, mas conforme a legislação poderá ser sancionada ou vetada pelo Governador do estado do Espírito Santo. 
incapacidades sociais e momentâneas. Com a possibilidade de educar pela Arte, o professor pode ensinar a seus alunos a verem e a estabelecerem relações da Arte com a própria vida, analisando o fenômeno, e como ele se revela, por trás das amarras sociais que usa como máscaras o sistema.

As diversas formas de excluir o d iferente o outro, já havia sido comentada por (LANDOWSKI, 2002), quando não admitimos o outro como alteridade e diferença que deve ser admitido entre os demais indivíduos de uma sociedade, aqui permanece uma bipolarização entre o normal e o patológico, o igual e o desigual, o branco e o negro, o nativo e o estrangeiro; essa preocupação em identificar o outro, gera uma preocupação extrema que foge aos princípios do respeito às diferenças e da própria humanidade.

Os museus e as fundações devem seguir esse eixo sócio antropológico de nossa contemporaneidade, a união e admissão do outro, não como eu aceito este ou aquele, mas uma assimilação do diferente na sua forma mais complexa, como a diversidade da contemporaneidade nos remete e nos diz a todo instante por meio dos textos apresentados, seja em um filme, em uma peça teatral, em uma instalação,uma fotografia, um desenho ou seja, nos diversos modos que a arte possa se apresentar.

\section{Reflexão final}

O preconceito está nas formas mais intrínsecas do ser humano, isso se dá com relação ao nível econômico, as questões de gênero, cor e raça e aparecem constantemente nas mídias audiovisuais, nos corredores da escola, em casa, na igreja, e o professor de arte tem uma tarefa árdua e transdisciplinar que é a de promover a visualização desses diversos textos sincréticos que aparecem na vida dos estudantes, de uma maneira crítica e reflexiva.

A nova forma de Arte que vai redefinir nossas concepções acerta do comércio, das relações, da amizade, da produção da ciência, da criatividade, de certa forma advém da matemática, das formulas binárias, mas como romper essa dicotomia que grita como um fractal frio que se desnuda sem os sentimentos de um sujeito humano? A bipolaridade dessa transição também afeta as ciências, e o homem.

\footnotetext{
Quando partes inteiras de nossas vidas caem na abstração devido à mudança de escala da globalização, quando as funções básicas de nosso cotidiano são gradualmente transformadas em produtos de consumo incluídas as relações humanas, que se tornam um verdadeiro interesse da indústria, parece muito lógico que os professores de artes, e os artistas procurem rematerializar essas funções e esses processos, devolver concretude ao que se furta à nossa vista. Não como objetos, o que significar e cair na armadilha da reificação, mas como suportes de experiências: a arte, ao tentar romper a lógica do espetáculo, restituinos o mundo como experiência vivida (BOURRIAUD, p. 32, 2004).
}

Como a massa que perpetua uma história, uma relação, uma lenda, o sistema econômico nos priva progressivamente dessa experiência única, e cabe a nós, inventar modos de representação dessa realidade não vivida. Por meio de vivências e experiências múltiplas.

O objetivo da arte desde a pré-história sempre foi o de desenvolver ferramentas 
para que o homem pudesse ver a dimensão do universo que o cerca além do alcance dos seus próprios sentidos. Foi através da arte que desenvolvemos as linguagens necessárias para formular os conceitos como história, humanidade e natureza, e também foi e continua sendo com a imaginação que conquistamos e por meio do nosso evolucionário convívio com a arte que formulamosa nossa relação com tudo o que é sagrado e religioso.

Como a massa que perpetua uma história, um relação, uma lenda, o sistema econômico nos priva progressivamente dessa experiência única, e cabe a nós, inventar modos de representação dessa realidade não vivida. Por meio de vivências e experiências múltiplas.

Esta aí a importância em promover e integrar as diversas manifestações da Arte com a escola e com os museus. A arte é um meio pelo qual tanto o educador como o educando expõem suas angústias e expectativas sociais, além de promover uma leitura crítica diante a realidade em que está inserido. Na maioria das vezes, não é possível ver, em nossas obras atuais, agonias, explorações, perversões, abusos, vícios e abortos e tudo que é tabu em nossa sociedade, como a sexualidade, a loucura e a política parafraseando Michel Foucault, em a Ordem do discurso (1971).

Adorno completa seu pensamento sobre a Arte com uma visão integradora com relação à crítica social ao sistema vigente. A integração da Arte na educação é imprescindível para o desenvolvimento do potencial crítico-social da humanidade.

A Arte não deve ser julgada pelos governantes como certa ou errada e ficar á margem de uma decisão que vai além dos seus campos de estudo e pesquisa, a arte educação, artes visuais e digitais devem ser respeitadas como veículo critico e de quebra de tabus existentes na sociedade. São esses mesmos tabus ${ }^{8}$ que muitas vezes a tornam doente em sua essência pois não admite o outro, a outra forma, o diferente, o estrangeiro em sua forma mais implícita.

Se a Arte não se colocar como tal, ela poderá desaparecer diante do sistema capitalista e financeiro.Em meados da década de 1960, ele defende que nenhum princípio deveria ser mais importante para a educação do que o de se prevenir contra Auschwitz, e que se esse princípio não estava sendo suficientemente defendido pelos educadores, novas tragédias similares poderiam ocorrer (ADORNO, 1968).

Por fim, é necessário um esforço conjunto das instituições envolvidos na educação das crianças, jovens e, sobretudo, que os governos, por meio de suas Secretarias de Educação e de Cultura, e os movimentos da sociedade civil organizada adotem uma postura efetiva para garantir a cidadania aos nossos jovens cidadãos, rompendo essa visão dualista e fundamentalista que ora é pressionada pela burguesia dominante, ora é pressionada por nossos políticos fundamentalistas e segregadores. Ao adotar uma política segregadora, passional, preconceituosa e principalmente, promover a censura de um movimento artístico, a Arte está sendo cercada e cerceada de todos os lados que permeiam esse tabu sexual, político e religioso. A arte não deve ser submetida a limites, pois a Arte, de fato deve ser livre. 


\section{Referências}

ADORNO, T. W. O fetichismo na música e a regressão da audição, 1963. Introdução à controvérsia sobre o positivismo na sociologia alemã, 1974. .et al. Teoria da cultura de massa: introdução, comentário e seleção de Luiz Costa Lima. 3. ed. Rio de Janeiro: Paz e Terra,1982.

ALMEIDA, Paulo Mendes. De Anita ao museu. São Paulo, Perspectiva, 1976.

BARROS,Diana Luz Pessoa de. A construção discursiva de discursos intolerantes. In: Preconceito e Intolerância-reflexões linguistico-discursivas, São Paulo: Universidade Presbiteriana Mackenzie, 2011, 255-270.

BENJAMIM. Walter, Magia e técnica, e política: ensaios sobre literatura e história da cultura, Tradução de Sergio P.Rovanet, 7ª. ed. São Paulo: Brasiliense,1994. v.1.

BOURRIAUD, Nicolas. Pós-produção: como a arte reprograma o mundo contemporâneo, SP, Martins Fontes, 2009.

CID 10. Classificação Estatística Internacional de Doenças e Problemas Relacionados com a Saúde, vol.01, Organização Mundial de Saúde, Ed USP, 2013.

DUILIO, B. Filho, Pequena Historia das Artes no Brasil, 2 edição, Átomo, Rio de Janeiro, 2008.

FREUD, Sigmund. Obras Completas - Vol. 11 - Totem e Tabu - Contribuição À História do Movimento psicanalítico e outros textos. Companhia da Letras, 1986.

LANDOWSKI. Eric, Presenças do outro: ensaios de sociossemiótica, São Paulo: Editora Perspectiva, 2002.

LOUREIRO,R.; DELLA FONTE, Sandra F. Industria cultural e educação: em tempos pósmodernos. São Paulo: Papirus, 2010.

GREIMAS, Algirdas. Maupassant a semiótica dos textos: exercícios práticos. Tradução de Teresinha Oenning e Carmen Lúcia Cruz Lima Gerlach. Florianópolis, Ed. da UFSC, 1993.

Du sensil. Paris: ÉditionsduSeuil, 1983.

JUNG, C. Gustav. O Homem e seus símbolos, Ed. Nova Fronteira, 1968

FOUCAULT,Michel. A Ordem do Discurso, Éditions Gallimard, Paris, 1971.

Arte, Epistemologia Filosofia e a História da Medicina, Rio de Janeiro, Ditos e Escritos Vol VII, 1 ed, 2011.

PATTO, Maria Helena Souza. Perspectiva acerca do preconceito, 1 ed., Casa do Psicólogo, 2008. 